\title{
Experimental and Numerical Evaluation of the Ablation Process of Carbon/Carbon Composites Using High Velocity Oxygen Fuel System
}

\author{
Xueling Fan, Peng Jiang, Biao Li, Xiaochao Jin, and Yong Zhao \\ State Key Laboratory for Strength and Vibration of Mechanical Structures, School of Aerospace Engineering, \\ Xian Jiaotong University, Xian 710049, China \\ Correspondence should be addressed to Xueling Fan; fanxueling@mail.xjtu.edu.cn
}

Received 12 February 2017; Revised 20 April 2017; Accepted 3 May 2017; Published 24 May 2017

Academic Editor: Ying Li

Copyright (C) 2017 Xueling Fan et al. This is an open access article distributed under the Creative Commons Attribution License, which permits unrestricted use, distribution, and reproduction in any medium, provided the original work is properly cited.

\begin{abstract}
The ablation process of carbon/carbon $(\mathrm{C} / \mathrm{C})$ composites was tested under hypersonic flowing propane flame. The microstructures of $\mathrm{C} / \mathrm{C}$ composites were characterized and the numerical analysis was performed. Two typical ablation morphologies of the carbon fibers, which are drum-like and needle-like shapes, were observed depending on the alignments of fibers to the flame directions. Temperature fields in the composites were analyzed using finite element method, and the mechanisms that govern the formation of different ablation behaviors were elucidated. For paralleled fiber bundles, the highest temperature situates in the middle parts underlying the ablation pits, where the drum-like shape is formed. For perpendicular fiber bundles, the highest temperature appears at the turning point between the transverse section and the surface of fiber, which leads to the gradual ablation from the fiber surface toward the axis, and eventually the formation of the needle-like shape.
\end{abstract}

\section{Introduction}

Carbon/carbon (C/C) composites are widely used as thermalstructural materials due to their lightweight and excellent thermal and mechanical properties. Ablation resistance is one of the key properties that characterize the performances of these composites in extremely high temperature conditions. The ablation resistance of $\mathrm{C} / \mathrm{C}$ composites is expected to be further improved to satisfy demands for the new generation of hypersonic vehicles operating in the extreme environment with high heat flux, high-pressure airflow, and high-speed erosion of particles.

Previous studies on the relationship of microstructure and ablation resistance of $\mathrm{C} / \mathrm{C}$ composites have been performed to clarify their ablation mechanisms. Tzeng and Chr [1] investigated the evolution of microstructure and properties of phenolic resin-based carbon/carbon composites during pyrolysis at different temperatures up to $2500^{\circ} \mathrm{C}$. Yin et al. [2] found that the $\mathrm{C} / \mathrm{C}$ composites have typical rough laminar pyrocarbon structure and ablation always tends to start at interfaces, defects, and pores. Deng et al. [3] investigated densification behavior and microstructure evolution of $\mathrm{C} / \mathrm{C}$ composites prepared by chemical vapor infiltration method. Farhan et al. [4] showed three-dimensional C/C composites comprising four reinforcement directions (4D) densified using a hybrid densified process. The microstructure evolution process of the carbon matrix showed that the ablation mainly first occurred at the interfaces of the PyC and the active spots where interfaces crystal defects and impurity particles exist $[2,5]$. For $4 \mathrm{D} \mathrm{C/C}$ composites, the ablation also starts at the weakest and porous primary carbon matrix, and it takes place in the following order: first in the primary carbon matrix, then in the fiber, and finally in the secondary carbon matrix [6]. In addition, effects of the degree of graphitization and microstructures on the ablation mechanisms, as well as the microstructure evolution, of $\mathrm{C} / \mathrm{C}$ composites have been preliminary investigated in previous studies [7-11].

Recently, numerical works have been mainly focused on the ablation rates of thermal protection materials. A few works have paid attentions to the mechanisms that govern 


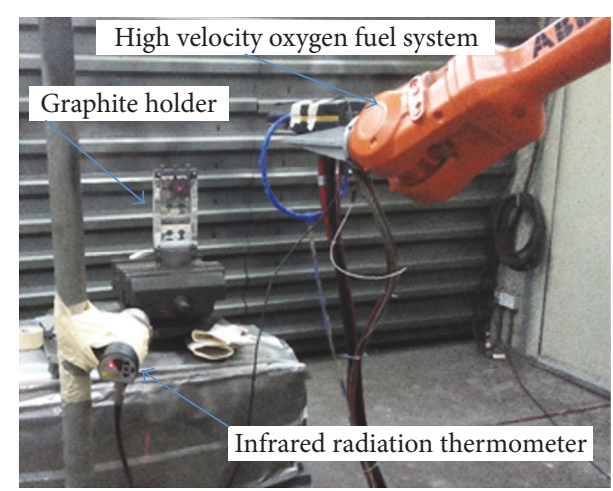

(a)

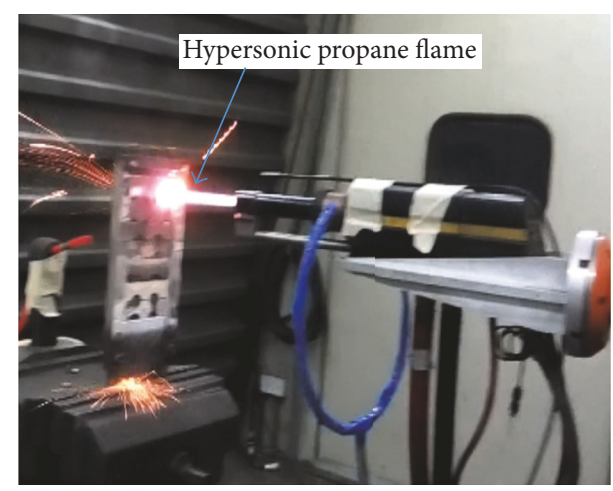

(b)

FIGURE 1: The high velocity oxygen fuel system.

the evolutions of ablated shape and microstructures [12-15]. In [16], flow-field temperature contours were simulated by the integrated TITAN-GIANTS code. Predicted shape change and temperature histories generally agree well with the data obtained from the arc-jet tests. Helber et al. [17] simulated the flow field and the temperature field of a low-density carbon-bonded carbon fiber composite in the atmospheric entry plasmas environment. Fang et al. [18] simulated the velocity field, temperature field, and pressure field around ablation pit to demonstrate the formation mechanism of "skeleton structure." Paglia et al. [19] simulated the pyrolysis and erosion of the ablator by implementing a complex finite element model, which results in very good agreement with experimental evidences. Very encouraging results were especially obtained in terms of surface insulation capacity and surface recession.

However, the ablation process of $\mathrm{C} / \mathrm{C}$ composites is complicated because it is related to both environmental conditions and microstructures of materials and has not been fully revealed so far. In this work, the ablation process and resistance of the $\mathrm{C} / \mathrm{C}$ composites were investigated. The ablation mechanism of the composites was elucidated by numerical analysis.

\section{Experiments}

The preform for preparing $\mathrm{C} / \mathrm{C}$ composites was needled carbon fiber felts with a density of $0.40 \mathrm{~g} / \mathrm{cm}^{3}$. The felts were infiltrated by an isothermal chemical vapor infiltration process to prepare $\mathrm{C} / \mathrm{C}$ composites with a density of approximately $1.75 \mathrm{~g} / \mathrm{cm}^{3}$. The $\mathrm{C} / \mathrm{C}$ composites were machined to size of $\Phi 9 \mathrm{~mm} \times 3 \mathrm{~mm}$.

The ablation tests were carried out in a flowing propane torch environment provided by high velocity oxygen fuel system (Praxair, JP8000, USA). The pressures were selected as $1.1 \mathrm{MPa}$ and $0.65 \mathrm{MPa}$, whereas the flux was $5.08 \mathrm{~L} / \mathrm{s}$ and $1.47 \mathrm{~L} / \mathrm{s}$ for oxygen and propane, respectively. The samples were exposed to the propane flame parallel to the axial orientation of the sample for $60 \mathrm{~s}$. The distance between the sample and the nozzle tip was $140 \mathrm{~mm}$. In the experiments, the temperature on the sample surface was measured by an infrared radiation thermometer (LumaSense IMPAC, IMPAC ISQ 5). The temperature of propane flame was about $2500^{\circ} \mathrm{C}$ at the ablation center. The velocity of the flame provided by high velocity oxygen fuel system (HVOF, Praxair, JP8000, USA) was estimated based on the relationship between the velocity of the propane flame and the distance from the nozzle tip to the sample which was provided by the manufacturers (Praxair Technology, Inc., USA). The velocity of propane flame was about $2000 \mathrm{~m} / \mathrm{s}$. During the test, the ablation gun was ignited firstly. After the flame became steady, the ablation gun was set vertical to the sample surface. The high velocity oxygen fuel system for the ablation experiments was illustrated in Figure 1. The microstructure and morphology of samples before and after ablation were analyzed using scanning electron microscopy (SEM, FEI Quanta 400). Three ring-shaped zones were marked as Zone 1, Zone 2, and Zone 3 according to the distances from the center of sample (Figure 2(a)). The distances from the center of sample for Zone 1, Zone 2, and Zone 3 were $3.5 \mathrm{~mm} \sim 4.0 \mathrm{~mm}, 2.5 \mathrm{~mm} \sim$ $3.0 \mathrm{~mm}$, and $0.5 \mathrm{~mm} \sim 1.0 \mathrm{~mm}$, respectively.

\section{Results and Discussion}

The $\mathrm{C} / \mathrm{C}$ composites exhibit two different morphologies according to the fiber direction (Figure 2(b)), namely, fiber bundles parallel to the cross section of the specimen (Direction I) and fiber bundles perpendicular to the cross section (Direction II). Figure 3 illustrates the morphologies of Directions I and II for Zone 1, Zone 2, and Zone 3 in $\mathrm{C} / \mathrm{C}$ composites after ablation. For Direction I, Zone 1 exhibits a typical microstructure of carbon fibers coated with pyrolytic carbon (Figure 3(a)). Several ablation pits with uniformly distributed drum-like fiber bundles were clearly observed. Many ablated pits with diameters ranging from about $5 \mu \mathrm{m}$ to $10 \mu \mathrm{m}$ were formed after short-term ablation, which located along the direction of upper fiber bundles (white arrows in Figure 3(a)). Underlying paralleled fiber bundles were clearly observed in the center of the ablated pits. Such ablated pits might be formed due to the low ablation resistance of pyrolytic carbon along the direction of upper paralleled fiber bundles. Zone 3 carbon was located at the 


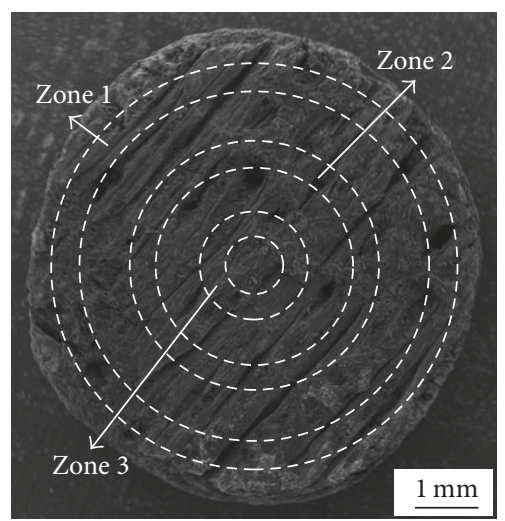

(a)

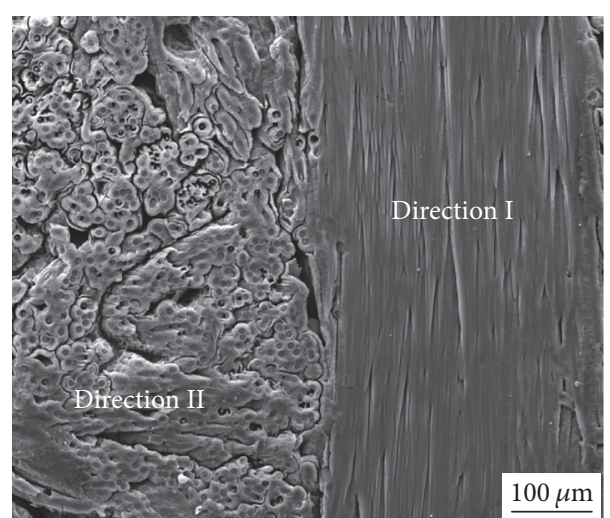

(b)

FIGURE 2: (a) SEM micrograph of C/C composite sample with increasing distance from the center (Zone 1:3.5 mm 4.0 mm, Zone 2: $2.5 \mathrm{~mm} \sim$ $3.0 \mathrm{~mm}$, and Zone 3: $0.5 \mathrm{~mm} 1.0 \mathrm{~mm}$ ); (b) SEM micrograph of C/C composites.

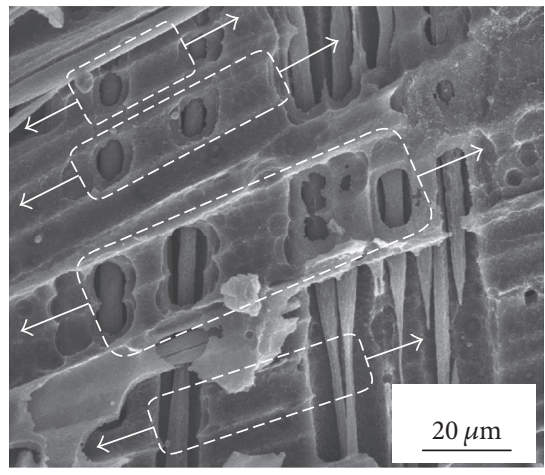

(a)

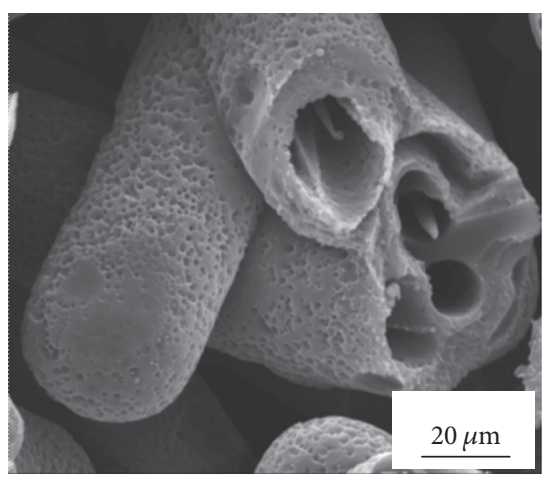

(d)

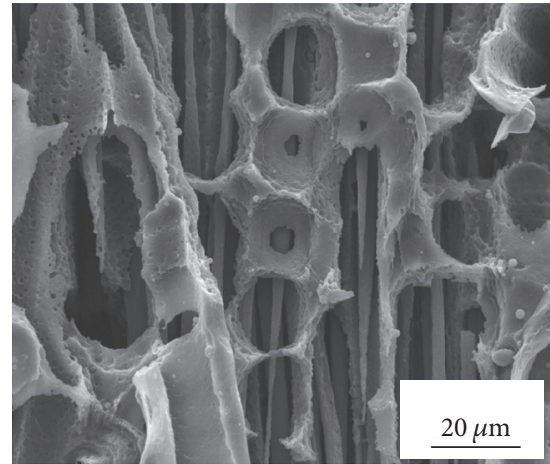

(b)

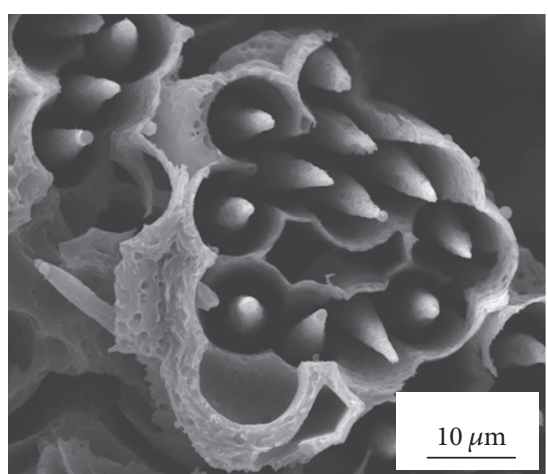

(e)

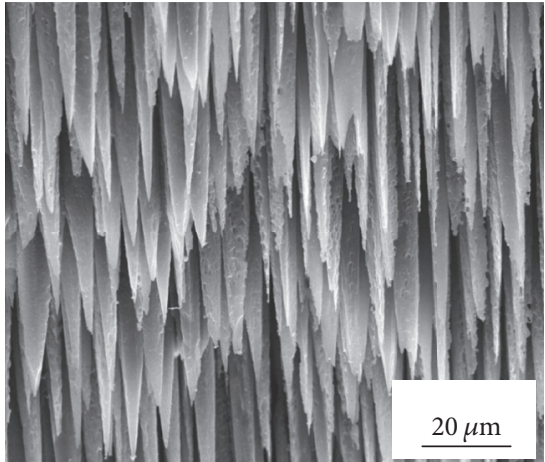

(c)

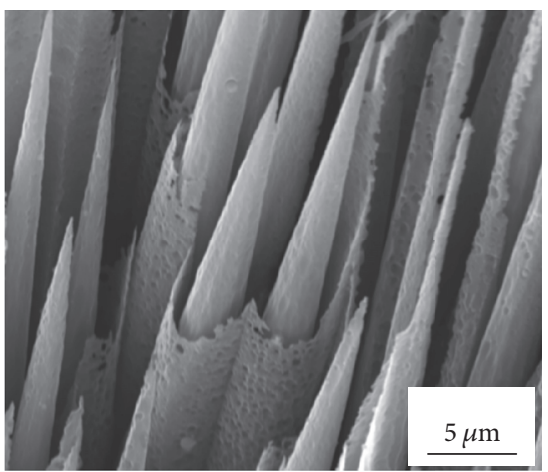

(f)

Figure 3: SEM morphologies of Directions I and II for Zone 1, Zone 2, and Zone 3 in C/C composites after ablation. (a), (b), and (c) are morphologies of Zone 1, Zone 2, and Zone 3 in Direction I, respectively; (d), (e), and (f) are those of Zone 1, Zone 2, and Zone 3 in Direction II, respectively.

center of samples, which suffered the highest temperatures. Thus underlying paralleled fiber bundles exhibited a drumlike shape. With increasing the degree of ablation, the ablated pits expanded gradually and coalesced eventually. Lots of underlying paralleled drum-like fiber bundles in the center of ablated pits were almost burnt out (Figure 3(b)). The upper pyrolytic carbon was gradually burnt out, leading to the fact that the underlying paralleled fiber bundles were exposed to the ablation flame directly (Figure 3(c)). Ablation behaviors of Direction I were characterized clearly by comparing the microstructures shown in Figures 3(a), 3(b), and 3(c). For Direction II, fiber bundles gradually 


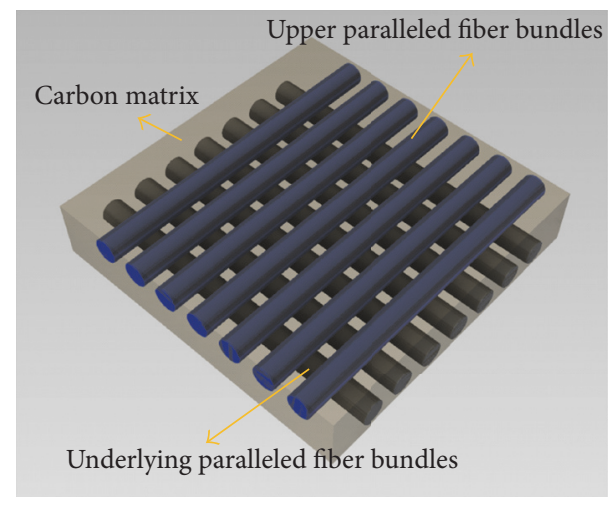

FIGURE 4: Schematic of paralleled carbon fibers and carbon matrix in $\mathrm{C} / \mathrm{C}$ composites (Direction I).

evolved from the well wrapped state to the needle-like shape with almost exhausted pyrolytic carbon, approaching the ablation center region. Perpendicular fiber bundles were fully wrapped with pyrolytic carbon in Zone 1 (Figure 3(d)), being far away from the hot ablation center. The ablation resistance of the interfaces between carbon fibers and pyrolytic carbon was the lowest, leading to the interfacial degradation (Figure 3(e)). Perpendicular fiber bundles with needle-like shapes were exposed during the ablation process because the antiablation properties of pyrolytic carbons were much lower than those of carbon fibers (Figure 3(f)). Fiber chippings were clearly observed on the tips of such needle-like shapes. This was the dominant failure mode of perpendicular fiber bundles, which was in agreement with the results reported by Li et al. [20].

Based on the experimental observations, it is shown that the temperature distributions and alignments of carbon fibers have significant influences on the formations of different morphologies in the composites after the ablation. In order to qualitatively study the effects of the above two factors, finite element simulations are carried out to obtain the temperature fields with different fiber alignment.

The finite element model adopted in this work was built based on the geometrical characteristics of the $\mathrm{C} / \mathrm{C}$ composites. A schematic of paralleled carbon fibers and carbon matrix in $\mathrm{C} / \mathrm{C}$ composites (Direction I) is shown in Figure 4 , in which the upper paralleled fibers, the underlying paralleled fibers, and carbon matrix are denoted, respectively. Figure 5(a) is the illustration of cross section view. Based on the experimental observation, during the ablation process, the upper paralleled fibers are gradually burnt out or denuded, and a concave surface will appear, as shown in Figure 5(b). Thus, the finite element model shown in Figure 6(a) can be used to investigate the problem.

Herein, temperature is a function of the distance from the center of $\mathrm{C} / \mathrm{C}$ composite. In this work, we use two models to represent the ablation morphologies of fiber bundles in Directions I and II, as shown in Figures 6(a) and 6(d). The diameters of the fiber are assumed as $7 \mu \mathrm{m}$ and their lengths are $100 \mu \mathrm{m}$. The density, thermal conductivity, and

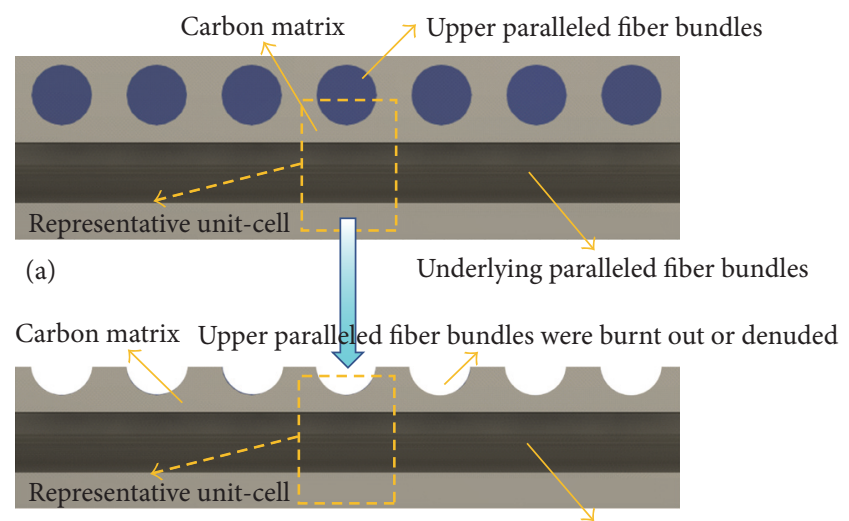

(b)

Underlying paralleled fiber bundles

FIgURE 5: Representative unit-cell of the C/C composites with a single paralleled fiber (Direction I).

specific heat of fiber are $1750 \mathrm{~kg} / \mathrm{cm}^{3}, 20 \mathrm{~W} /\left(\mathrm{m}^{\circ}{ }^{\circ} \mathrm{C}\right)$, and $800 \mathrm{~J} /\left(\mathrm{kg} \cdot{ }^{\circ} \mathrm{C}\right)$ and $1000 \mathrm{~kg} / \mathrm{cm}^{3}, 5 \mathrm{~W} /\left(\mathrm{m} \cdot{ }^{\circ} \mathrm{C}\right)$, and $720 \mathrm{~J} /\left(\mathrm{kg} \cdot{ }^{\circ} \mathrm{C}\right)$ for carbon matrix. The transient heat transfer analyses were performed with ABAQUS. A sink temperature (i.e., the thermal load) of $2500^{\circ} \mathrm{C}$ is assumed based on the experimentally measured temperature of propane flame. The sink temperature is instantly imposed on the heat transfer surfaces of the models (see Figure 6). It is known that the local ablation of the composites always takes place within a very short time prior to reaching the uniform temperature field. In this work, the temperature distributions in the fibers and matrix presented were calculated at the moment of $5 \mathrm{~s}$. Such a short time is not enough to reach a uniform temperature within the composites. As a result, a temperature gradient is formed. Other conditions and properties are based on the experimental observations and measurements.

The temperature distributions are illustrated in Figures 6 and 7. Note that we focus on the qualitative temperature distributions within the fiber and carbon matrix rather than their exact values. Thus, the contour results are dimensionless. For I, the temperature above the fiber bundle is obviously lower than surrounding matrix (Figures 6(b) and 6(c)). The relative high temperature in surrounding matrix leads to their rapid ablation and the gradual exposure of the fiber in flame. The temperature distribution in the fiber bundle (Figure 7(a)) indicates that its easier for the middle section to suffer from ablation than both ends. The above mechanisms lead to the drum-like shape of I after ablation. For II, the perpendicular fiber model has similar mechanism with paralleled model. As shown in Figures 6(e) and 6(f), the temperature in the carbon matrix is higher than that of fiber bundle, leading to their earlier ablation, and the fiber bundle is gradually exposed in the flame. The nondimensionalized temperature distribution along the path, which starts from center of the fiber top surface to a certain point on the vertical surface, is illustrated in Figure 7(b). It can be seen that the turning point between fiber top surface and vertical surface has the highest temperature. Therefore, the fiber bundle is gradually 


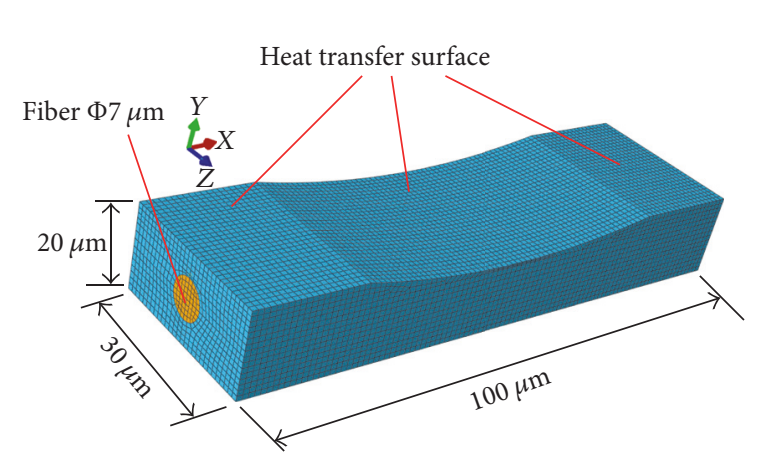

(a)
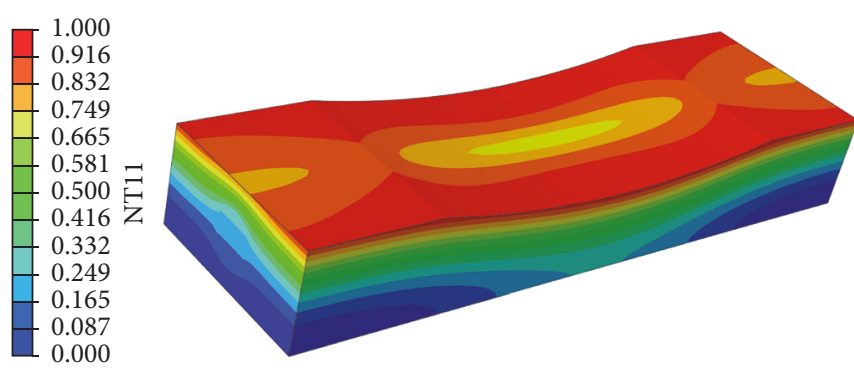

(b)

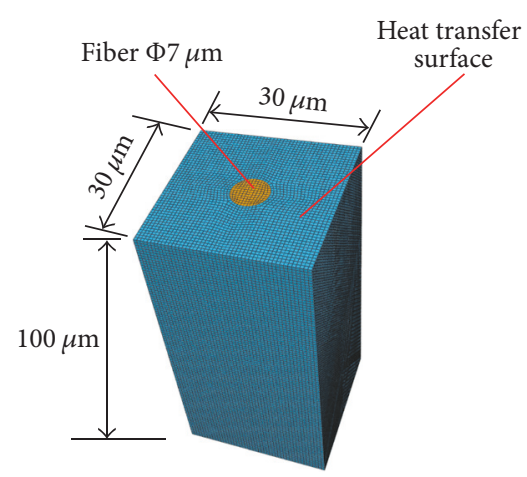

(d)

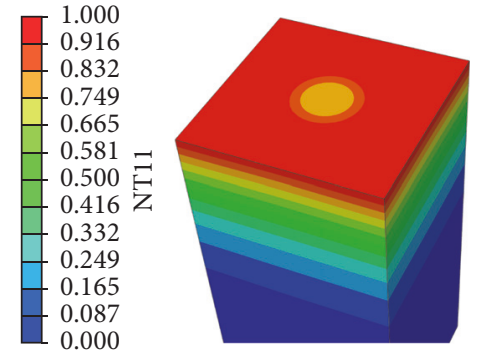

(e)

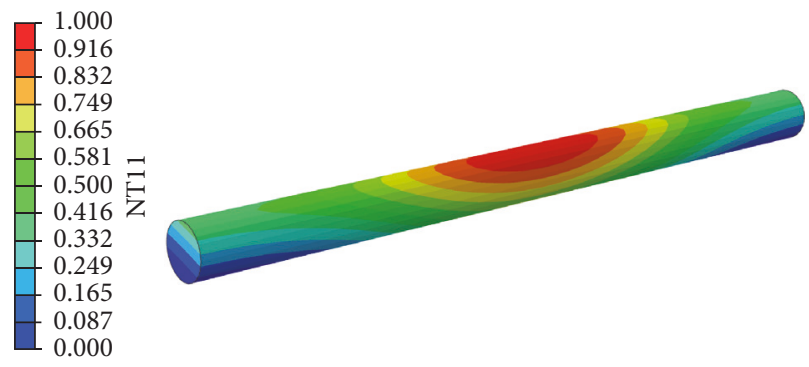

(c)

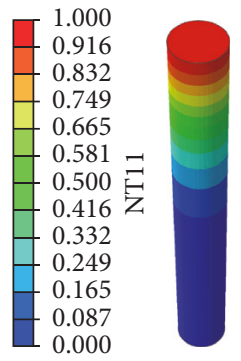

(f)

Figure 6: Numerical simulation of the C/C composites with a single paralleled (Direction I) and a single perpendicular fiber (Direction II), respectively: (a) and (d) are geometrical dimensions; (b) and (e) are overall temperature field; (c) and (f) are temperature field of the fiber bundle (note that the temperature contours are plotted in dimensionless units, where temperature value of 0 refers to the lowest temperature and value of 1 denotes the highest temperature).

ablated from the vertical surface to the center, leading to the needle-like shape of II. The above results suggest that different ablation failure mechanisms of two oriented fiber bundles are mainly caused by the mismatch of thermal properties of fiber and matrix.

\section{Conclusions}

The ablation properties of $\mathrm{C} / \mathrm{C}$ composites were tested under hypersonic flowing propane flame. Fiber bundles in two obvious different directions were observed. The ablation mechanism significantly depends on both the distance from ablation center and the fiber direction. With increasing distance, the microstructure of fiber bundles paralleled to the cross section changed from a typical morphology of carbon fibers coated with carbon to distributed ablation pits with drum-like fiber bundles and eventually to fractured fiber bundles. Fiber bundles perpendicular to the cross section, which were well wrapped with pyrolytic carbon, gradually evolved to exposed needle-like fiber bundles with almost exhausted pyrolytic carbon. Numerical simulations were performed to reveal the microstructure evolution and the ablation mechanism of $\mathrm{C} / \mathrm{C}$ composites. Temperature distributions of paralleled fiber bundles indicated that its middle section was vulnerable to ablation, which led to the formation of drum-like microstructure. Temperature distributions of perpendicular fiber bundles showed that the highest temperature situated at the edge of the fiber top surface, which made the fiber bundle ablated gradually from vertical surface to the center and eventually led to 


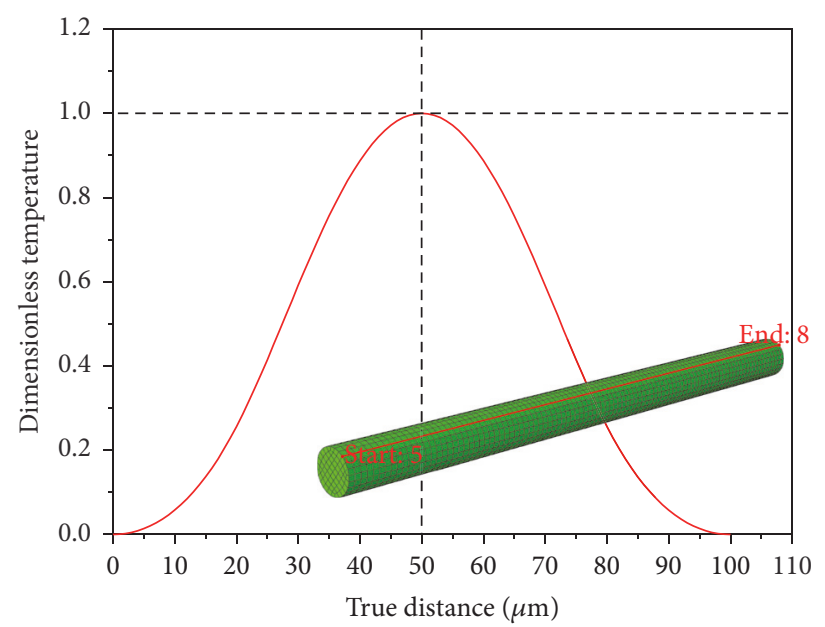

(a)

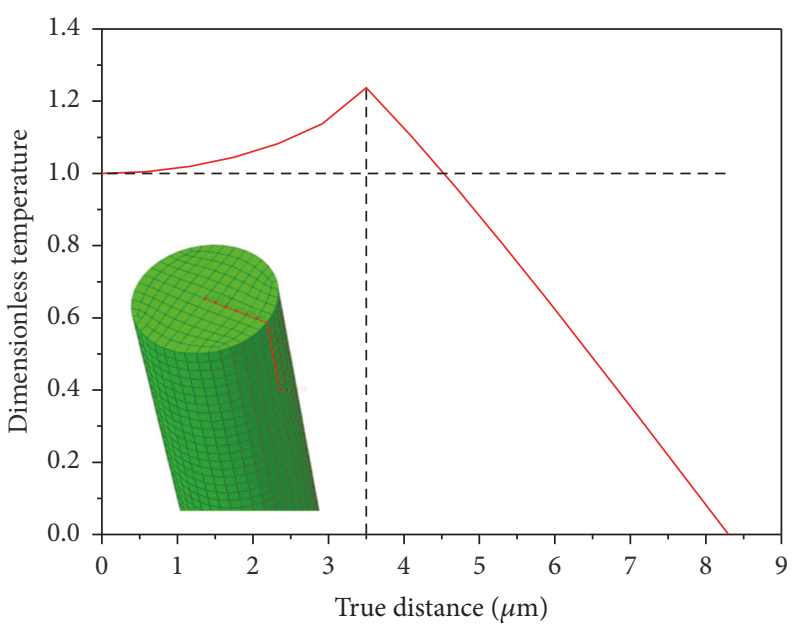

(b)

Figure 7: Temperature distribution of (a) Direction I: paralleled fiber bundle along fiber's length and (b) Direction II: perpendicular fiber bundle from center of the fiber top surface to a position on the vertical surface, respectively.

the needle-like microstructure. Microstructure evolution and ablation mechanism revealed in this work can provide a better understanding of the ablation mechanism of $\mathrm{C} / \mathrm{C}$ composites.

\section{Conflicts of Interest}

The authors declare that there are no conflicts of interest regarding the publication of this paper.

\section{Acknowledgments}

This work was supported by China 973 Program (2013CB035700) and NSFC (11472204, 11272259, and 11321062).

\section{References}

[1] S.-S. Tzeng and Y.-G. Chr, "Evolution of microstructure and properties of phenolic resin-based carbon/carbon composites during pyrolysis," Materials Chemistry and Physics, vol. 73, no. 2-3, pp. 162-169, 2002.

[2] J. Yin, X. Xiong, H. Zhang, and B. Huang, "Microstructure and ablation performances of dual-matrix carbon/carbon composites," Carbon, vol. 44, no. 9, pp. 1690-1694, 2006.

[3] H. Deng, K. Li, H. Li, X. Li, L. Zhang, and W. Cao, "Densification behavior and microstructure of carbon/carbon composites prepared by chemical vapor infiltration from xylene at temperatures between 900 and $1250^{\circ}$ C," Carbon, vol. 49, no. 7, pp. 25612570, 2011.

[4] S. Farhan, R. Wang, K. Li, and C. Wang, "Sublimation and oxidation zone ablation behavior of carbon/carbon composites," Ceramics International, vol. 41, no. 10, pp. 13751-13758, 2015.

[5] J. C. Han, X. D. He, and S. Y. Du, "Oxidation and ablation of 3D carbon-carbon composite at up to $3000^{\circ} \mathrm{C}$," Carbon, vol. 33, no. 4, pp. 473-478, 1995.

[6] S. Kumar, J. Kushwaha, S. Mondal, A. Kumar, R. K. Jain, and G. Rohini Devi, "Fabrication and ablation testing of $4 \mathrm{D} \mathrm{C} / \mathrm{C}$ composite at $10 \mathrm{MW} / \mathrm{m}^{2}$ heat flux under a plasma arc heater," Materials Science and Engineering: A, vol. 566, pp. 102-111, 2013.

[7] X. Zhang, X. Li, G. Yuan, Z. Dong, G. Ma, and B. Rand, "Large diameter pitch-based graphite fiber reinforced unidirectional carbon/carbon composites with high thermal conductivity densified by chemical vapor infiltration," Carbon, vol. 114, pp. 59-69, 2017.

[8] S. Farhan, K.-Z. Li, L.-J. Guo, Q.-M. Gao, and F.-T. Lan, "Effect of density and fibre orientation on the ablation behaviour of carbon-carbon composites," New Carbon Materials, vol. 25, no. 3, pp. 161-167, 2010.

[9] K. Zhou, H. J. Hoh, X. Wang et al., "A review of recent works on inclusions," Mechanics of Materials, 2013.

[10] W. Li, H. J. Li, S. Y. Zhang, J. F. Wei, J. Wang, and Z. Q. Li, "Effect of high temperature treatment on the microstructure and mechanical properties of binary layer textured 2D C /C composites," New Carbon Materials, vol. 26, pp. 328-334, 2011.

[11] L.-L. Zhang, H.-J. Li, K.-Z. Li et al., "Improved surface wettability of water by applying $\mathrm{SiC} / \mathrm{Ti} 6 \mathrm{Al} 4 \mathrm{~V}$ coatings on carbon/carbon composites," Advances in Materials Science and Engineering, vol. 2013, Article ID 703610, p. 5, 2013.

[12] J. H. Koo, D. W. H. Ho, and O. A. Ezekoye, "A review of numerical and experimental characterization of thermal protection materials-Part I. Numerical modeling," in Proceedings of the 42nd AIAA/ASME/SAE/ASEE Joint Propulsion Conference \& Exhibit, Sacramento, Ca, USA, 2006.

[13] S. B. Shi, L. J. Li, J. Liang, and S. Tang, "Surface and volumetric ablation behaviors of SiFRP composites at high heating rates for thermal protection applications," International Journal of Heat and Mass Transfer, vol. 102, pp. 1190-1198, 2016.

[14] W. Chen, "Numerical analyses of ablative behavior of C/C composite materials," International Journal of Heat and Mass Transfer, vol. 95, pp. 720-726, 2016.

[15] W. J. Li, H. M. Huang, and X. L. Xu, "A coupled ther$\mathrm{mal} /$ fluid/chemical/ablation method on surface ablation of charring composites," International Journal of Heat and Mass Transfer, vol. 109, pp. 725-736, 2017. 
[16] Y. K. Chen, F. S. Milos, D. C. Reda, and D. A. Stewart, "Graphite ablation and thermal response simulation under arcjet flow conditions," in Proceedings of 36th AIAA Thermophysics Conference 2003, Orlando, Fa, USA, 2003.

[17] B. Helber, O. Chazot, A. Hubin, and T. E. Magin, "Microstructure and gas-surface interaction studies of a low-density carbon-bonded carbon fiber composite in atmospheric entry plasmas," Composites Part A: Applied Science and Manufacturing, vol. 72, pp. 96-107, 2015.

[18] X. Fang, F. Liu, B. Xia, D. Ou, and X. Feng, "Formation mechanisms of characteristic structures on the surface of $\mathrm{C} / \mathrm{SiC}$ composites subjected to thermal ablation," Journal of the European Ceramic Society, vol. 36, no. 3, pp. 451-456, 2016.

[19] L. Paglia, J. Tirillò, F. Marra et al., "Carbon-phenolic ablative materials for re-entry space vehicles: Plasma wind tunnel test and finite element modeling," Materials and Design, vol. 90, pp. 1170-1180, 2016.

[20] X.-H. Li, Q.-Z. Yan, Y.-Y. Mi, Y.-J. Han, X. Wen, and C.-C. Ge, "The influence of ablation products on the ablation resistance of $\mathrm{C} / \mathrm{C}-\mathrm{SiC}$ composites and the growth mechanism of $\mathrm{SiO}_{2}$ nanowires," Chinese Physics B, vol. 24, no. 2, 2015. 

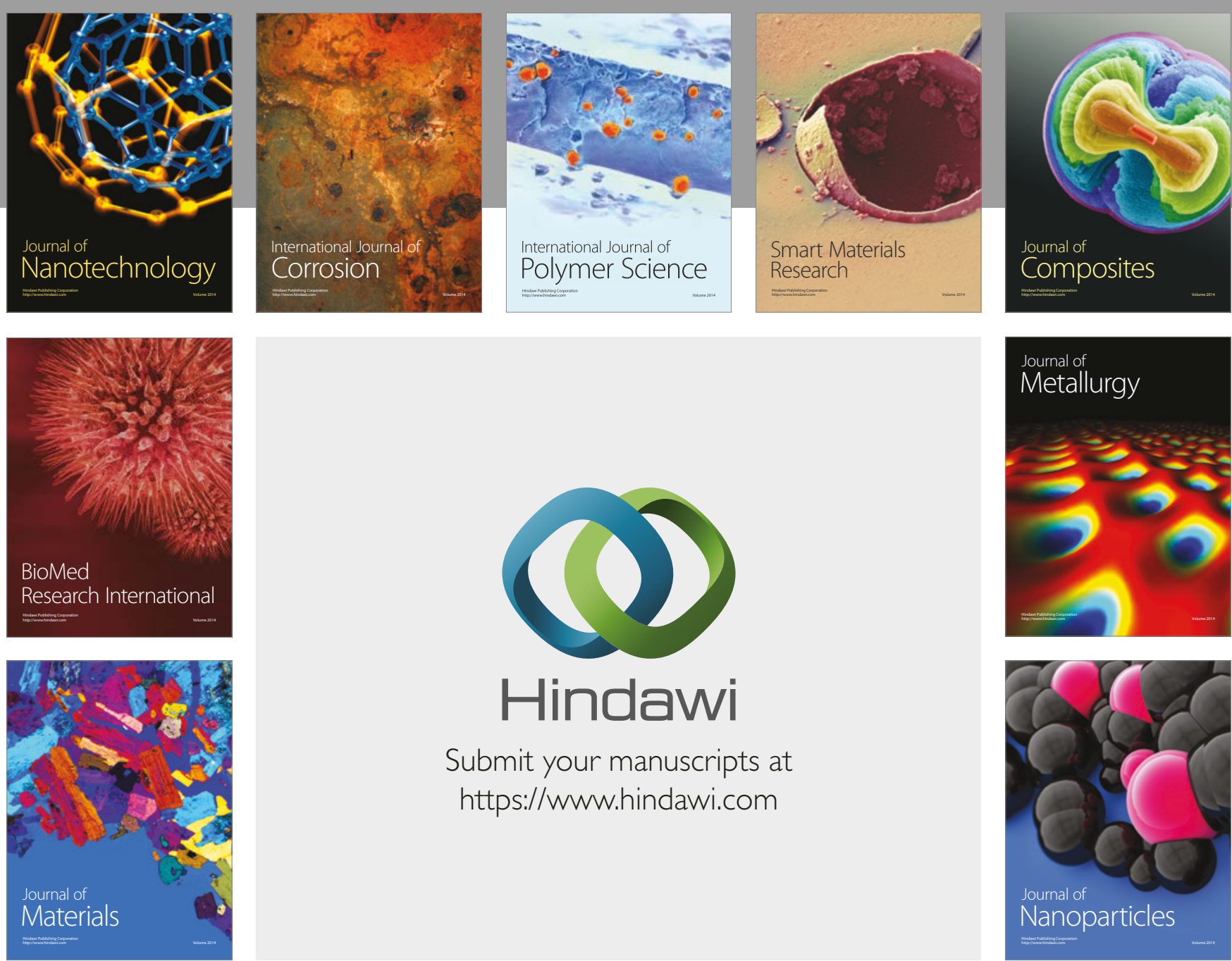

\section{Hindawi}

Submit your manuscripts at

https://www.hindawi.com
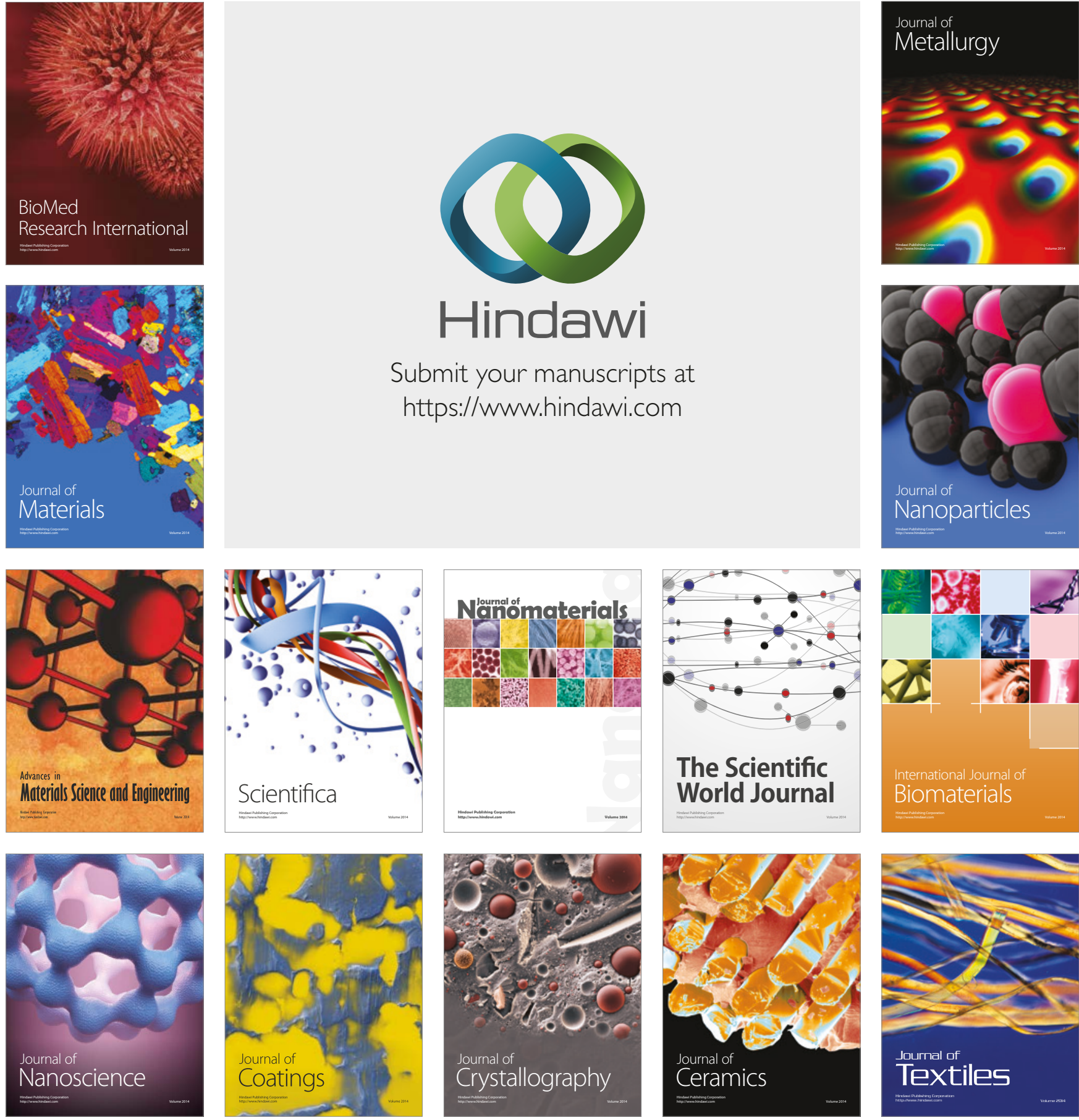

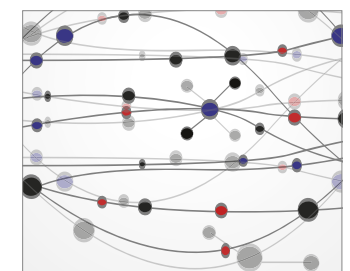

The Scientific World Journal
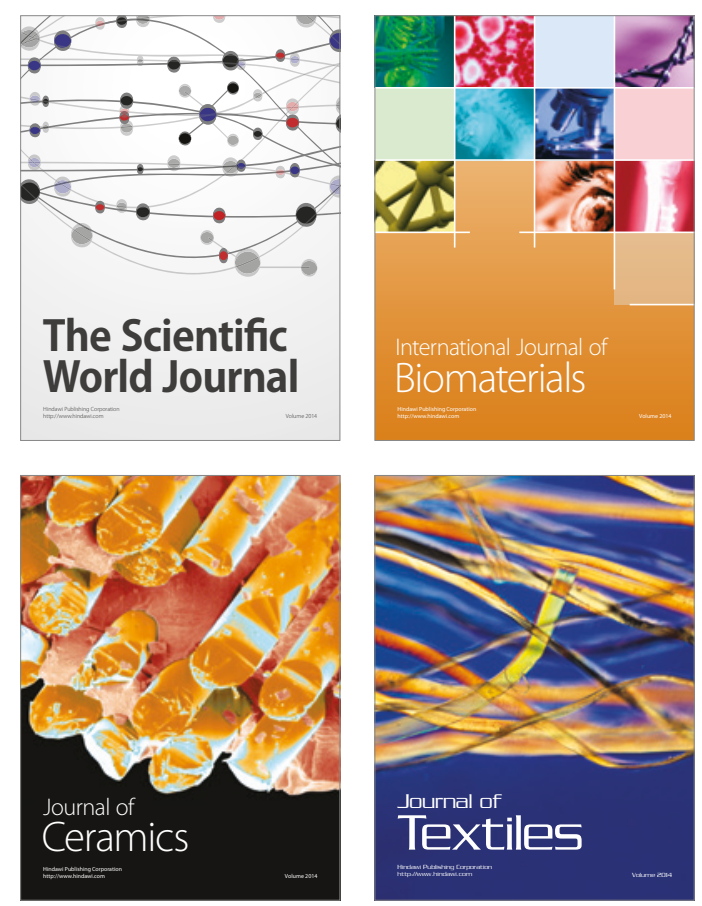